\title{
Interventional Radiology Practice in Saudi Arabia: Are We Driving on Soft Sand?
}

It is too common and alarming story that despite interventional radiology's (IR) central role in patient care it suffers from a relative anonymity. Many practitioners, residents, and medical students in Saudi Arabia and worldwide have a misconception about IR or even never heard about it. ${ }^{[1-5]}$ This is a critical issue that carries several major implications on the future of profession.

Maintaining IR excellence and promoting the specialty in clinical practice is multifaceted, yet it can be approached at two different levels to protect the profession from sinking in soft sand.

1. Solid ground: First, we need to solidify the ground IR is driving through and improve the clinical environment that surrounds IR practice. This requires expanding mutual clinical responsibilities and effectively participating in multidisciplinary decisions. Further, IR staff should be proactive in educating other clinical services about IR and its expanding role in clinical practice and familiarizing them about new techniques and minimally invasive procedures. The continuing competition between IR and other services results in poor influx of quality cases, which leads to growing frustration of the interventional radiologists. Some interventional radiologists, in fact, started to do more diagnostic radiology (DR) work or even engage in hospital administrative tasks as a result. This overlap leads to ambiguous future in the eyes of residents who may be interested in pursuing their career in IR.

2. Broaden the base: Second is to broaden the presence of IR as a vital medical specialty by providing qualified interventionists. While the number of interventional radiologists in Saudi Arabia is probably the largest in the Arab world, it remains short of matching the increasing demand, given the high prevalence of diabetes, peripheral vascular disease, end-stage renal disease, and hepatocellular carcinoma. To overcome staff shortage, several measures have to be considered at the legislative, administrative, and clinical levels to help recruiting the best and brightest medical graduates to IR training.

a. Marketing IR to medical students: As medical students progress from medical school to residency and beyond, other specialists rather than interventional radiologists themselves will mold their perceptions about IR. Although some medical schools offer a dedicated IR clerkship, as few as $5.5 \%$ of the medical students participate in the elective rotation. ${ }^{[6]}$ Over the past decade, interest has been growing in the specialty of IR, with a resultant significant increase in the number of individuals applying for training. ${ }^{[7]}$ However, the levels of exposure of medical students to IR and understanding of the specialty remain low. ${ }^{[2]}$ In addition, other medical specialties routinely perform minimally invasive, image-guided procedures that overlap with those performed by interventional radiologists; therefore, it can be very confusing for medical students to understand when and how IR physicians are involved in patient care. ${ }^{[8]}$ Early exposure to IR through introductory lectures has been shown to increase medical students' understanding of IR and interest in pursuing the specialty as a career. ${ }^{[3]}$

b. IR rotations during DR residency training: During the 4-year DR programs, the resident is supposed to complete a total of three IR rotations. The residency curriculum may have to provide longer rotations to further expose residents to the concepts of IR. Interventionists can use phantoms and simulators to credential radiology residents for minor procedures such as vascular access, image-guided drainage, and biopsies. However, one must document that residents are competent before they can perform these procedures with indirect supervision. Rewarding promising residents by sponsoring them to attend IR conferences is important to make IR rotation attractive.

c. Enhancement of clinical knowledge during radiology residency training: Many of the DR residents avoid direct patient contact. While interventional radiologists have always received excellent technical training, we must mature the clinical skills that complement our technical strength. This clinical training must be started early during residency program, as it is near impossible to master the gamut of interventional techniques along with the inherent clinical competency necessary in a year-long fellowship. The Pan Arab Interventional Radiology Society (PAIRS), Saudi Interventional Radiology Society (SIRS), and other IR professional bodies should effectively propose these curricular changes to the legislative boards and residency training programs to furnish a greater clinical foundation.

d. IR involvement in DR teaching: Most IR consultants focus on clinical service by doing more procedures, distancing them from academic activities. IR consultants should be more involved in teaching case scenarios and basic techniques. Furthermore, IR consultants should be involved in many 
clinical-radiological meetings and should encourage residents to attend these meetings. Participation in journal clubs of residency training programs is the key to stimulate residents to evaluate new research in the IR domain and to advocate evidence-based practice.

e. IR involvement in DR qualifying and certifying examination process: The weight of IR component in the blueprint of the DR board examination is negligible; in fact, it is commonly a small part of other subspecialty component. Considering IR as standalone subspecialty in the board examination will raise the importance of IR specialty. The presence of interventional radiologists on radiology examination committees adds to the breadth of knowledge of IR specialty. Incorporating interventional skills along with clinical care material in both the written and oral examinations is essential.

f. Research in IR: Introducing IR technical advances into practice requires extensive preclinical and clinical research to demonstrate safety and effectiveness. However, interventional radiologists' contribution to literature has decreased significantly over the past 10 years, and primary authors are more likely to be nonradiologists. ${ }^{[9]}$ This shift in research productivity may be accompanied by a parallel shift of service to physicians who mastered the technique and produced its relevant research. The PAIRS and SIRS initiative to promote research by conducting a scientific meeting and establishing a journal will hopefully increase IR contribution to the body of literature originating from the region. Being a part of international multicenter trials with engagement of residents in training is an important step forward.

g. IR fellowship training programs: Having local IR fellowship program is an important factor in marketing for the specialty. The fellowship started a decade ago as a single institute and as a 1-year fellowship. The Saudi Commission for Health Specialties has approved a 2-year fellowship program starting from 2013. The number of trainees has increased over the past 3 years from 2 to 8 .

h. It is collaborative efforts between medical schools, DR programs, and IR societies to share resources, educate, and recruit clinical-minded medical students and residents who want to provide minimally invasive options, as we continue to see the rapid evolution of our specialty. The key to IR's current and future success is the recruitment of passionate and highly motivated medical students and residents.
I hope that the international IR community joins us in this task.

\author{
Abdulkader Abdulmohsen Alkenawi \\ Department of Medical Imaging, \\ King AbdulAziz Medical City, Jeddah, Saudi Arabia \\ E-mail:akenawi@gmail.com
}

\section{References}

1. Alshumrani GA. Awareness of interventional radiology among final-year medical students and medical interns at a university in Southwestern Saudi Arabia. Saudi Med J 2013;34:841-7.

2. Commander CW, Pabon-Ramos WM, Isaacson AJ, Yu H, Burke CT, Dixon RG. Assessing medical students' knowledge of IR at two American medical schools. J Vasc Interv Radiol 2014;25:1801-6, 1807.e1-5.

3. Ghatan CE, Kuo WT, Hofmann LV, Kothary N. Making the case for early medical student education in interventional radiology: A survey of $2^{\text {nd }}$ year students in a single U.S. institution. J Vasc Interv Radiol 2010;21:549-53.

4. Kattapuram TM, Sheth RA, Ganguli S, Mueller PR, Walke TG. Interventional radiology symposium for medical students: Raising awareness, understanding, and interest. J Am Coll Radiol 2015;12:968-71.

5. Leong S, Keeling AN, Lee MJ. A survey of interventional radiology awareness among final-year medical students in a European country. Cardiovasc Intervent Radiol 2009;32:623-9.

6. Nissim L, Krupinski E, Hunter T, Taljanovic M. Exposure to, understanding of, and interest in interventional radiology in American medical students. Acad Radiol 2013;20:493-9.

7. Harsha AK, Schmitt JE, Stavropoulos SW. Match day: Online search trends reflect growing interest in IR training. J Vasc Interv Radiol 2015;26:95-100.

8. Lakhan SE, Kaplan A, Laird C, Leiter Y. The interventionalism of medicine: Interventional radiology, cardiology, and neuroradiology. Int Arch Med 2009;2:27.

9. Ray CE Jr., Gupta R, Blackwell J. Changes in the American interventional radiology literature: Comparison over a 10-year time period. Cardiovasc Intervent Radiol 2006;29:599-604.

This is an open access article distributed under the terms of the Creative Commons Attribution-NonCommercial-ShareAlike 3.0 License, which allows others to remix, tweak, and build upon the work non-commercially, as long as the author is credited and the new creations are licensed under the identical terms.

\begin{tabular}{|l|l|}
\multicolumn{2}{c|}{ Access this article online } \\
\hline Quick Response Code: & Website: \\
\hline
\end{tabular}

How to cite this article: Alkenawi AA. Interventional radiology practice in Saudi Arabia: Are we driving on soft sand?. Arab J Intervent Radiol 2017;1:8-9. 